\title{
Design Approach of Hologram Tutor: A Conceptual Framework
}

\author{
Mohd Khairulnizam Ramlie, Ahmad Zamzuri Mohamad Ali, and Muhammad Ihsan Rokeman
}

\begin{abstract}
Hologram tutor is a new approach that has potential in attracting students' attention, especially the young generation who lack interest with traditional delivery methods. In addition, the use of hologram tutor serves as an alternative strategy to deliver information in a more interesting manner, which consequently will provide new experience to the students. Nevertheless, the actual human design use of a hologram tutor may cause some inconvenience or uneasiness among students, adversely affecting students' emotion in learning. Such a phenomenon is called Uncanny Valley, which was developed through a study by Masahiro Mori in 1970, who also developed a graph to explain such a concept. Against this backdrop, this paper proposes a conceptual framework for the design approach of a hologram tutor with the main aim of enhancing students' positive emotion in learning. Essentially, this conceptual framework was developed grounded on relevant theories and principles highlighted in the current literature. Additionally, this paper suggests potential future studies to validate the proposed framework.
\end{abstract}

Index Terms-Character design, hologram tutor, uncanny valley, emotions, learning.

\section{INTRODUCTION}

The advancement of multimedia technology is rapidly improving, especially in the field of digital animations. This eventually makes the design and development of the multimedia elements become more easier and consequently expanding its use in various fields, including in education [1]-[3]. In view of the rapid development of this technology, the need of innovating its use in the teaching and learning process has become more urgent; in order to ensure that such a process will be more attractive and effective [1], [4]. Among the innovations, specifically in the visualization and presentation aspect is hologram technology [5]. Some studies had shown that the use of human characters at various realistic levels can produce different emotional effects. For example, a study was done on video games [6], [7] and a pedagogy agent [8], stated that the use of more realistic characters may give

Manuscript received September 13, 2019; revised December 2, 2019. This work was supported in part by Ministry of Education Malaysia and Universiti Pendidikan Sultan Idris (UPSI), who awarded a FRGS Grant FRGS/1/2018/SS109/UPSI/01/1. Design Approach of Hologram Tutor: A Conceptual Framework.

Mohd Khairulnizam Ramlie and Ahmad Zamzuri Mohamad Ali are with Faculty of Art, Computing and Creative Industry, Universiti Pendidikan Sultan Idris 35900 Tanjong Malim, Perak, Malaysia (e-mail: nizamramlie@gmail.com, zamzuri@fskik.upsi.edu.my).

Muhammad Ihsan Rokeman is with the Department of Science, Mathematic and Computer, Polytechnic Sultan Azlan Shah, 35950 Tanjong Malim, Perak, Malaysia (e-mail: ihsan.psas@gmail.com). users a more comfortable effect. However, there are still lacking in in-depth studies regarding students' emotional aspects when learning with realistic holographic representations as tutors. It is a very important thing to be identified because the use of holographic representations of tutors can influence the students' emotion when receiving any parts of information in the classroom. Hence the realistic level of the holographic representative needs to be examined to ensure that students are comfortable with the presence of the character. After all, the medium used is totally different from the conventional method of receiving images through screens of computers, tablets and smartphones.

\section{HOLOGRAM IN EDUCATION}

The word hologram originated from the Greek term 'holos', meaning an overall view [9]. In principle, a hologram consists of two light sources interacting with one another to create 3D visual [10]. In other words, a hologram is a combination of reflected $2 \mathrm{D}$ visuals that are projected from a display device, such as a screen or a projector that gives a 3D look [9], [11]. To date, holograms are viewed as a 3D visualization technology for future generation [12]. Moreover, a hologram technique can present objects or characters in such a way that makes it looks appealing in delivering information more innovatively to the users. In addition, holograms has been acknowledged to be highly appealing to attract users' attention, especially among the younger generation who lack interest with the traditional delivery methods [13]. Nonetheless, the use of holograms may have several negative effects on the older generation who lack experience in using current technology [14].

Admittedly, the use of a holographic medium is not restricted to specific aspects as it encompasses multiple disciplines such as education, advertisement, and entertainment among others [15]. Viewed from the educational standpoint, holograms have a unique ability to attract the interest and attention of users and can make the information processing in the user's memory to be more effective [16], [17]. Furthermore, the use of holograms will be able to influence the teaching and learning condition [18]. In this regard, holograms have strong potential to serve as an effective instructional medium to help the teaching and learning process. Taking cognizance of its many benefits, many efforts have been put in place to explore its educational attributes that can be applied in teaching and learning [9]. Given that the use of holograms in the educational realm entails detailed studies [19], researches on holograms must focus on the design principles that can further enhance its effectiveness in the teaching and learning process. Despite 
having a host of educational benefits, such a focus is essential to deal with potential pitfalls, such as the acceptance of this novel tool by users of various ages [14]. Fig.1 shows a hologram based on a real human character [5].

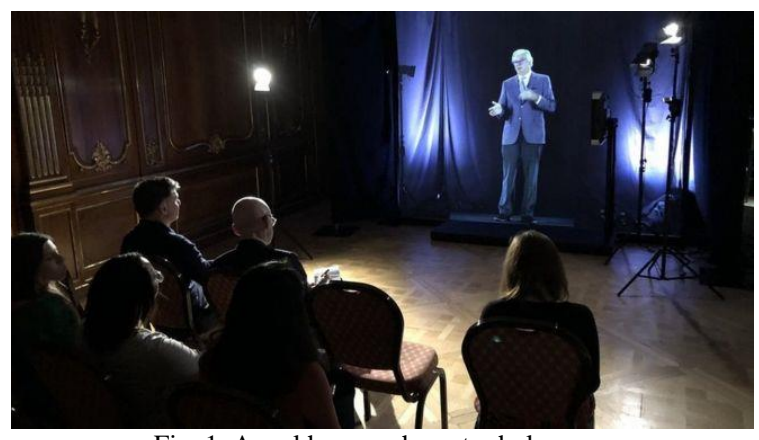

Fig. 1. A real human character hologram.

\section{EMOTIONS AND ACCEPTANCE}

In general, emotion in learning is an internal feeling experienced by students during learning [20], [21]. In principle, emotion can be divided into two different categories, namely positive and negative emotion [20], [22]-[25]. Positive emotion experienced by students during learning is the feeling of enjoyment, excitement, interest, and accomplishment.

In addition, the emotion experienced by students can influence their level of motivation during learning sessions [26], [27]. In particular, positive emotion experienced can raise students' motivation; in contrast, negative emotion can lower their motivation that demotivates them to continue engaging in learning [20], [23], [28].

Taking into consideration of such emotion, it is imperative to carry out studies to identify the ideal character design for hologram tutor. This, to ensure that positive emotion can be realized in students' learning sessions. To date, most studies carried out mainly focuses on the effect of emotion induced by the character design in the field animation [29]-[32] and computer games [9], [10]. Thus far, studies focusing on the effect of the character design on students' emotion are seriously lacking or almost non-existent for hologram tutor. Nevertheless, the research findings of studies on animation and computer games suggest that the diversity of appearance and personality of a character design can have a profound impact on users' emotion. Surely, such a revelation needs to be given a strong emphasis in the design process of characters for computer applications [29], [33], including hologram tutor.

In addition to the emotional aspect, the acceptance of the use of a hologram tutor also need to be seriously considered. Such a consideration is important when dealing with the use of new technology as several factors, such as the age of users, can influence their acceptance of such technology [34]. According to Prensky [34], the age level can be divided into two categories, namely digital native and digital immigrant. Digital natives refer to the group of users born after 1990, while digital immigrants are those who were born before 1990. Nonetheless, there are other opinions stating that the difference in the acceptance of a new technology corresponds with the age of users, implying that the older the users, the lower their acceptance of such technology [35].

Overall, this paper highlights the difference in the acceptance of new technology based on users' age. In this regard, the age difference between older and new generation needs to be taken into account in the use of a hologram tutor as a representation of a teacher in the classroom. Given that, its extensive use in the higher institutions of learning consisting of diverse students' population of various demographics, including age. More importantly, the effect of the acceptance of a hologram tutor can also influence the emotion of students in learning.

\section{THEORETICAL FRAMEWORK}

In this study, two related theories were used as the foundation for the conceptualization of the proposed framework. The first was the Control-Value Theory of Achievement Emotions [36], a theory that focuses on achievement emotions with which scholars can use in analyzing the causes of emotional changes and the effect of emotions experienced in learning sessions [37]. Essentially, achievement emotions are an emotion that is directly experienced by students while engaging in learning activities and also after the completion of learning activities [20], [24], [38]. Based on this theory, achievement emotions can be divided into three different values or dimensions, namely positive or negative emotional reaction, the level of emotional activation (activating or de-activating), and the focus of objects (activities or learning outcomes) [38]. Based on these three values, Pekrun et al. [36] conceptualized and developed a 3-dimensional taxonomy of achievement emotions as summarized in Table I.

TABLE I: THE 3-DIMENSIONAL TAXONOMY OF ACHIEVEMENT EMOTIONS BASED ON CONTROL-VALUE THEORY OF ACHIEVEMENT EMOTIONS

\begin{tabular}{|c|c|c|c|c|}
\hline \multirow[b]{2}{*}{ Ferus of object } & \multicolumn{2}{|c|}{ Positive } & \multicolumn{2}{|c|}{ Negative } \\
\hline & Activating & De-activating & Activating & De-activating \\
\hline $\begin{array}{l}\text { Fecus on } \\
\text { activities }\end{array}$ & Fun & Relaxed & Angry & Bored \\
\hline $\begin{array}{l}\text { Fecus on } \\
\text { learning } \\
\text { outcomes }\end{array}$ & $\begin{array}{l}\text { Happy. } \\
\text { Hope. } \\
\text { Proud. } \\
\text { Appeciated. }\end{array}$ & $\begin{array}{l}\text { Satisfied. } \\
\text { Relieved. }\end{array}$ & $\begin{array}{l}\text { Worry. } \\
\text { Stry. } \\
\text { Angry. }\end{array}$ & $\begin{array}{l}\text { Sad. } \\
\text { Frustrated. } \\
\text { Lost hope. }\end{array}$ \\
\hline
\end{tabular}

Based on this theory, students' learning motivation can be increased by promoting positive emotions. For instance, feeling of enjoyment when engaging in the learning activity could increase positive emotions. By contrast, negative emotions, such as bored could reduce students' motivation to engage in the learning activities [20]. As such, this theory can be referred for studies focusing on the dimension of the reaction of positive emotions and its impact on the learning motivation. Specifically, for the scope of this paper, study on the role of hologram tutor character design in enhancing positive emotions of students. Based on this theory, the appropriate character design of the hologram tutor that can optimally enhance students' positive emotions need to be identified. In addition, the hologram tutor characters that can 
activate (feeling of fun) and de-activate (feeling angry) need to be categorized for students of different age levels as well.

To enhance positive emotions in learning, numerous character design approach of the hologram tutor can be studied based on Uncanny Valley phenomenon. The phenomenon explains the relationship between level of realism of a character and human's emotion [39]. In this respect, the selection of characters with appropriate level of realism needs to be carried out in the development process of the hologram tutor. An animation character with too much realism can adversely affect users' emotions and feeling of comfort as they see such a character. Clearly, mistakes made in selecting proper level of realism could cause Uncanny Valley phenomenon, which might have an adverse severe effect on users' emotional state [32].

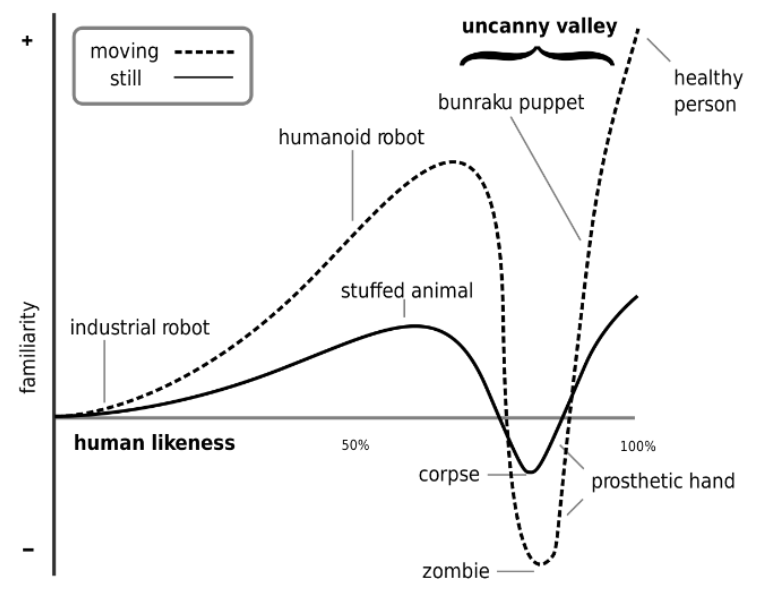

Fig. 2. The uncanny valley graph.

Clearly, a strong grasp of the Uncanny Valley phenomenon is vital in selecting the most appropriate design for the character of hologram tutor. As such, studies to examine such a phenomenon in determining the dynamic character deemed proper for the proposed hologram tutor to represent a teacher delivering his or her lessons in the classroom. As highlighted in the Mori's graph of Uncanny Valley, positive emotions increase with increasing realism of a character representing humans. However, for dynamic and static characters, the opposite is true in that users' emotions can reach a negative level when the character is in a horrible form or shape. Specifically, the level of comfort dropping as shown in the graph is called the Uncanny Valley phenomenon.

Such a phenomenon will occur when the character design approaches a realistic human, causing users to feel scared and horrible [40]. Nevertheless, the graph also shows that the level of emotions increases positively with the use of a real human character [39]. In addition, the same graph indicates that the dynamic character will be subjected to an extreme effect of the Uncanny Valley phenomenon compared to that of the static character. Thus far, hologram tutor character with different design approach has not been tested for its effects on users' comfort. Therefore, the selection of characters based on the Uncanny Valley phenomenon graph need to be further compared for hologram tutor condition. This is specifically on their impact on students' emotion in learning.

\section{CONCEPTUAL FrameWORK}

Based on the review of the literature pertaining to the relevant theories and principles of designs, this paper proposes a conceptual framework of hologram tutor character design as depicted in Fig. 3.

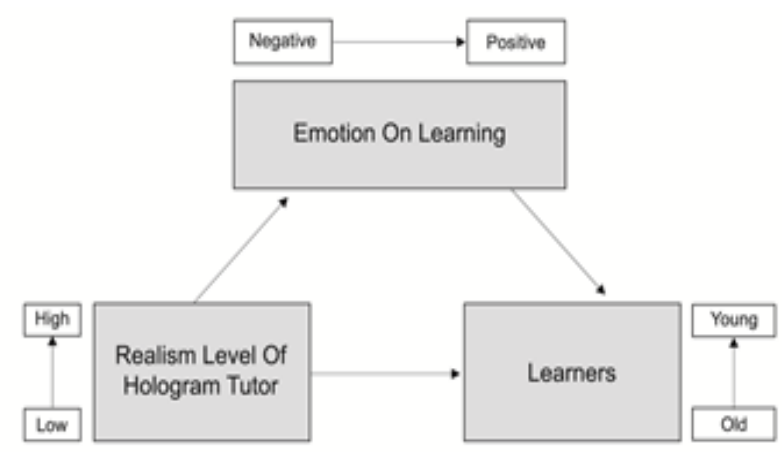

Fig. 3. Conceptual framework.

The realism level of a hologram tutor representing teacher plays an important role in determining students' emotions in learning. As such, selecting appropriate level of realism for such a representation requires careful considerations. Furthermore, the use of the hologram tutor encompasses a range of students' ages or generations, which might cause different emotion effects on such groups of students. In this regard, choosing an inappropriate realism level of the hologram tutor character may undermine students' emotions, which, according to the theory of Uncanny Valley can make them feel uncomfortable if the chosen realism is too high. This situation will disrupt the students' emotions, and at the same time will effect their motivation in learning. In particular, the realism level of a character is an important factor that needs to be given due consideration to avoid students from being uncomfortable when learning using a hologram tutor. In view of such a need, study to identify the most appropriate realism level of a hologram tutor character, which can truly represent a teacher in the classroom seems important.

Furthermore, the use of the appropriate level of realism can have positive emotional effect on students of various levels of age. Emotions in learning that are a person's inner feelings during the learning process need to be emphasized to ensure meaningful learning process happens. As such, positive and negative emotions effect need to be identified first to assist instructional designers in determining the appropriate character for the hologram tutor. Specifically, positive emotions, such as pleasure, excitement, interest, and satisfaction, can enhance students' motivation that encourages them to continue learning and receiving information more effectively. As such, the ideal character design of the hologram tutor has to be accurately identified to help enhance positive emotions, notably the state of pleasure, among students. The character design of the hologram tutor might be the primary cause of the change in students' emotions, the effect of which would have a profound effect on their learning. In particular, the level of realism of such a character that can activate positive emotions and de-activate negative emotions of students of various ages need to be categorized.

In addition, the differences in age might be one of the 
factors that have a strong influence on the acceptance of such a tutor and that have a profound effect on students' emotions. The students of different age levels may have different interaction effects, making a certain group of students, especially the older generation of students, to be indifferent to the use of novel technology, such as the hologram tutor. In contrast, the younger generation of students may find the hologram tutor to be a novel tool that can deliver information more efficiently with some excitement. Given that students of the institutions of higher learning are of various age levels, it becomes the imperative of researchers and scholars to examine and analyze the interaction of the use of the hologram tutor with respect to such a difference.

\section{FUTURE WORK}

In an effort to carry out this study, the researcher will conduct classes tutored by holographic characters catered to students from various ages. The researcher uses some methods to analyze the emotional impact and acceptance towards the use of holographic characters to represent tutors in classrooms. The respondents are grouped into categories as children, teenagers and adults. To analyze the acceptance level of the holographic characters, the researcher uses the User Experience Questionnaire UEQ [41] that is proven in its effectiveness. On the other hand, the emotional impact in tutorial sessions are examined through the Self-Assessment Manikin (SAM) [42] and Achievement Emotions Questionnaire (AEQ) [24]. Through the study, the effectiveness of the holographic representation of tutors for various age groups can be identified and achieved.

\section{CONCLUSION}

The use of holograms in education has been proven to be effective, made evidently from previous studies. More specifically, the use of holograms as a tutor to substitute the real teacher can help in attracting students' attention and deliver information more effectively in an innovative way than that of the traditional approach. As such, design principles aspects need to be given a strong emphasis. Which, inappropriate hologram tutor character design can cause negative emotions among students, the impact of which can demotivate them to stay in learning. Against such a backdrop, studies focusing on the effect of Uncanny Valley phenomenon on students' comfort and emotions seems important. As highlighted in the proposed conceptual framework, the level of realism of the character of hologram tutor is a major issue that needs to be addressed with extreme care, especially for students of various ages who may have different interaction effects.

\section{CONFLICT OF INTEREST}

The authors declare no conflict of interest.

\section{AUTHOR CONTRIBUTIONS}

Mohd Khairulnizam Ramlie conducted the research; Ahmad Zamzuri Mohamad Ali grant leader and research supervisor; Muhammad Ihsan Rokeman contribution for the knowledge; all authors had approved the final version.

\section{ACKNOWLEDGMENT}

The authors wish to acknowledge the support of the Ministry of Education and Sultan Idris Education University (UPSI), who awarded a FRGS Grant FRGS/1/2018/SS109/UPSI/01/1 research grant for this study.

\section{REFERENCES}

[1] C. K. Chan, "Use of animation in engaging teachers and students in assessment in Hong Kong higher education," Innovations in Education and Teaching International, vol. 52, no. 5, pp. 474-484, 2013.

[2] O. Kainz, F. Jakab and S. Kardoš, "The computer animation in education," in Proc. 2013 IEEE 11th International Conference on Emerging eLearning Technologies and Applications (ICETA), 2013.

[3] H. K. Çakmak and U. Kühnapfel, "Animation and simulation techniques for VR-training systems in endoscopic surgery," Computer Animation and Simulation 2000, Springer, Vienna, 2000.

[4] J.-C. Tu and Y.-H. Chiang, "The influence of design strategy of peer learning on 3-D software learning," Eurasia Journal of Mathematics, Science \& Technology Education, vol. 12, no. 5, pp. 1263-1271, 2016.

[5] L. Kelion, "'Hologram' lecturers to teach students at Imperial College London," November 2018.

[6] R. Daneels, S. Malliet, J. Koeman, and W. Ribbens, "The enjoyment of shooting games: Exploring the role of perceived realism," Computer in Human Behavior, vol. 86, pp. 330-336, 2018.

[7] E. Hudlicka, "Affective computing for game design," in Proc. the 4th Intl. North American Conference on Intelligent Games and Simulation (GAMEON-NA), Montreal, Canada, 2008.

[8] H. M. Najib and M. A. A. Zamzuri, "Kesan Tahap Realistik Karakter Animasi Talking-Head Ke Atas Emosi Dan Prestasi Pelajar: Satu Kajian Awal," Jurnal Teknologi Maklumat Dan Multimedia Asia-Pasifik, vol. 3, no. 2, pp. 13-25, 2014.

[9] H. Ghuloum, "3D hologram technology," in Proc. Informing Science \& IT Education Conference (InSITE) 2010, United Kingdom, 2010.

[10] J. Geng, "Three-dimensional display technologies," Advances in Optics and Photonics, pp. 456-535, 2013.

[11] S. A. Ahmad, I. M. Abdullahi, and M. Usman, "General attitude and acceptance of holography in teaching among lecturers in Nigerian colleges of education," IAFOR Journal of Education, vol. 3, no. SE, pp. 140-160, 2015.

[12] L. Yang, H. Dong, A. Alelaiwi, and A. El Saddik, "See in 3D: State of the art of 3D display technologies," Multimedia Tools and Applications, pp. 1-35, 2015.

[13] K. Worley, "Educating college students of the net generation," Adult Learning 22, pp. 31-39, 2011.

[14] M. Wójcik, "Holograms in libraries - The potential for education, promotion and services," Library Hi Tech, pp. 18-28, 2018.

[15] A. Elmorshidy, "Holographic projection technology: The world is changing," Journal of Telecommunications, vol. 2, no. 2, pp. 104-113, 2010 .

[16] A. Brown. (2017). DMN.Data.Stratergy.Technology. [Online]. Available:

https://www.dmnews.com/agencies/blog/13042200/3d-marketing-wit h-holograms

[17] B. Bach, R. Sicat, J. Beyer, M. Cordeil, and H. Pfister, "The hologram in my hand: How effective is interactive exploration of $3 \mathrm{D}$ visualizations in immersive tangible augmented reality?" IEEE Transactions on Visualization and Computer Graphics, vol. 24, no. 1, pp. 457-467, 2018

[18] R. A. Walker, "Holograms as teaching agents," Journal of Physics, 2013.

[19] N. D. A. H. N. M. M. Barkhaya, "A review of application of 3D hologram in education: A meta-analysis," in Proc. 2016 IEEE 8th International Conference on Engineering Education (ICEED), Kuala Lumpur, 2016.

[20] R. Pekrun, T. Götz, W. Titz, and R. P. Perry, "Positive emotions in education," Beyond Coping: Meeting Goals, Visions, and Challenges, 2002.

[21] H. M. Najib and M. A. A. Zamzuri, "Kesan Tahap Realistik Karakter Animasi Talking-Head Ke Atas Emosi Dan Prestasi Pelajar: Satu Kajian Awal," Jurnal Teknologi Maklumat Dan Multimedia Asia-Pasifik, vol. 3, no. 2, pp. 13-25, 2014. 
[22] K. Kwon, A. Hanrahan, and K. Kupzyk, "Emotional expressivity and emotion regulation: Relation to academic functioning among elementary school children," School Psychology Quarterly, vol. 32, no. 1, pp. 75-88, 2017.

[23] H. Lei and Y. Cui, "Effects of academic emotions on achievement among mainland chinese students: A meta-analysis," Social Behavior and Personality: An International Journal, vol. 44, no. 9, pp. 1541-1553, 2016.

[24] R. Pekrun, T. Goetz, A. Frenzel, P. Barchfeld, and R. Perry, "Measuring emotions in students' learning and performance: The achievement emotions questionnaire (AEQ)," Contemporary Educational Psychology, vol. 36, no. 1, pp. 36-48, 2011.

[25] R. Pishghadam, M. Zabetipour, and A. Afrooz, "Examining emotions in English language learning classes: A case of EFL emotions," Educational Research, vol. 26, no. 3, pp. 508-527, 2016.

[26] F. Ganotice, J. Datu, and R. King, "Which emotional profiles exhibit the best learning outcomes? A person-centered analysis of students' academic emotions," School Psychology International, vol. 37, no. 5, pp. 498-518, 2016.

[27] T. Goetz, R. Pekrun, N. Hall, and L. Haag, "Academic emotions from a social-cognitive perspective: Antecedents and domain specificity of students affect in the context of Latin instruction," British Journal of Educational Psychology, vol. 76, no. 2, pp. 289-308, 2006.

[28] C. Mega, L. Ronconi, and R. Beni, "What makes a good student? How emotions, self-regulated learning, and motivation contribute to academic achievement," Journal of Educational Psychology, vol. 106 no. 1, pp. 121-131, 2014.

[29] K. Zibrek, E. Kokkinara, and R. Mcdonnell, "The effect of realistic appearance of virtual characters in immersive environments — Does the characters personality play a role?" IEEE Transactions on Visualization and Computer Graphics, vol. 24, no. 4, pp. 1681-1690, 2018.

[30] J. Roxas, D. Richards, A. Bilgin, and N. Hanna, "Exploring the influence of a human-like dancing virtual character on the evocation of human emotion," Behavior \& Information Technology, vol. 37, no. 1, pp. 1-15, 2017.

[31] C. Mousas, D. Anastasiou, and O. Spantidi, "The effects of appearance and motion of virtual characters on emotional reactivity," Computers in Human Behavior, vol. 86, pp. 99-108, 2018.

[32] H. M. Najib, M. A. Zamzuri, and H. Anuar, "The effects of realism level of talking-head animated character on students pronunciation learning," in Proc. 2015 International Conference on Science in Information Technology (ICSITech), Yogyakarta, Indonesia, 2015.

[33] O. Korn, L. Stamm, and G. Moeckl, "Designing authentic emotions for non-human characters," in Proc. the 2017 Conference on Designing Interactive Systems, 2017.

[34] M. Prensky, "Digital natives, digital immigrants part 1," On the Horizon, pp. 1-6, 2001.

[35] S. Timmermann, "The role of information technology in older adult learning," New Directions for Adult and Continuing Education, pp. 61-71, 1998.

[36] R. Pekrun, "The control-value theory of achievement emotions: Assumptions, corollaries, and implications for educational research and practice," Educational Psychology Review, pp. 315-341, 2006.

[37] K. Muñoz, J. Noguez, L. Neri, P. M. Kevitt, and T. Lunney, "A computational model of learners achievement emotions using control-value theory," Journal of Educational Technology \& Society, pp. 42-56, 2016.

[38] A. Artino, E. Holmboe, and S. Durning, "Control-value theory: Using achievement emotions to improve understanding of motivation, learning, and performance in medical education: AMEE Guide No. 64," Medical Teacher, vol. 34, no. 3, pp. 148-160, 2012.

[39] M. Mori, "The uncanny valley," IEEE Robotics \& Automation Magazine, pp. 98-100, 2012.

[40] K. F. MacDorman, R. D. Green, C.-C. Ho, and C. T. Koch, "Too real for comfort? Uncanny responses to computer generated faces," Computers in Human Behavior, pp. 695-710, 2009.

[41] M. Schrepp et al., "Applying the user experience questionnaire (UEQ) in different evaluation scenarios," Design, User Experience, and Usability. Theories, Methods, and Tools for Designing the User Experience Lecture Notes in Computer Science, pp. 383-392, 2014.

[42] M. M. Bradley and P. J. Lang, "Measuring emotion: The self-assessment manikin and the semantic differential," Journal of Behavior Therapy and Experimental Psychiatry, vol. 25, no. 1, pp. 49-59, 1994.

Copyright (C) 2020 by the authors. This is an open access article distributed under the Creative Commons Attribution License which permits unrestricted use, distribution, and reproduction in any medium, provided the original work is properly cited (CC BY 4.0).

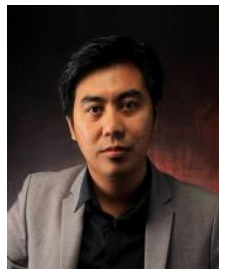

Mohd Khairulnizam Ramlie is studying for the doctor of philosophy in multimedia design, Faculty of Art, Computing and Creative Industry, Universiti Pendidikan Sultan Idris, Perak, Malaysia. He is currently a full time lecturer at the Department of Graphic Design and Digital Media, Faculty of Art \& Design, Universiti Teknologi MARA, Perak Branch, Seri Iskandar Campus, Perak, Malaysia. He obtained the bachelor's degree (hons) in graphic design and digital media in 2008, and received the master's degree in visual communication and new media in 2012, both from Faculty of Art and Design, Universiti Teknologi MARA, Malaysia.

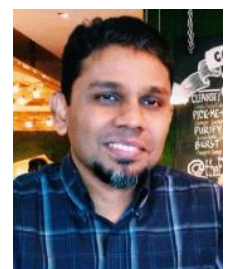

Ahmad Zamzuri Mohamad Ali is a professor of multimedia in the Faculty of Art, Computing and Creative Industry, Universiti Pendidikan Sultan Idris, Malaysia. He has a $\mathrm{PhD}$ in instructional multimedia from Universiti Sains Malaysia, the master in education and bachelor degree in electrical engineering from Universiti Teknologi Malaysia. Has taught both face-to-face and online classes in higher education for over 20 years. His research and publication interest is instructional technology, specifically in multimedia design, programming teaching and learning and hardware software interfacing. In his 10 years experience as an academic in UPSI, he has published 4 books, which one obtained National Book Award 2018 and over 100 articles in journals, chapter in books, national and international proceedings, and monthly periodical.

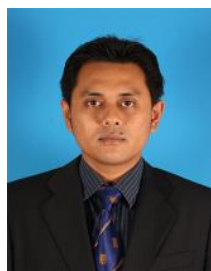

Muhammad Ihsan Rokeman is a PhD student in multimedia design, Faculty of Art and Creative Industry, Universiti Pendidikan Sultan Idris, Perak, Malaysia. Currently, he is a full-time lecturer in the Department of Mathematics, Science and Computers at Politeknik Sultan Azlan Shah, Perak, Malaysia. He obtained a bachelor degree of information technology (multimedia studies) from Universiti Kebangsaan Malaysia in 2005 and a master degree of multimedia education from Universiti Pendidikan Sultan Idris in 2015. 